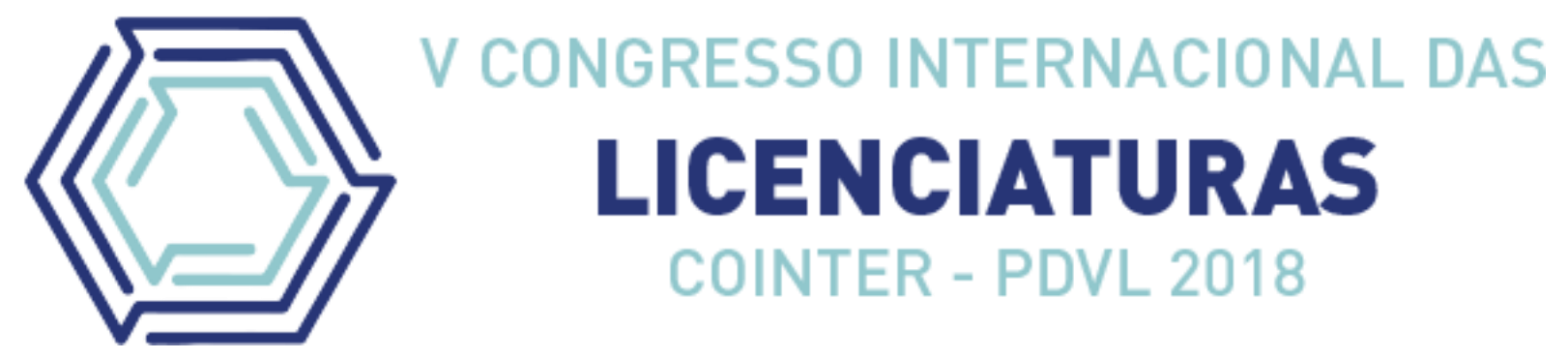

\title{
EDUCAÇÃO PREVENTIVA E PROMOÇÃO DA SAÚDE NA ESCOLA: CONHECENDO A GIÁRDIA E PREVENINDO A GIARDÍASE
}

\section{PREVENTIVE EDUCATION AND HEALTH PROMOTION AT SCHOOL: KNOWING GIARDIA AND PREVENTING GIARDIASIS}

\author{
Apresentação: Pôster \\ Ana Fernanda da Silva ${ }^{1}$; Igor Porleone de Souza Guimarães ${ }^{2}$; Jurecir da Silva ${ }^{3}$; \\ Marlúcia da Silva Bezerra Lacerda ${ }^{4}$
}

\section{DOI: https://doi.org/10.31692/2358-9728.VCOINTERPDVL.2018.00197}

\section{Introdução}

O agente etiológico da giardíase é um protozoário conhecido como Giardia lamblia. Os protozoários pertencem ao reino Protista, dentro do domínio Eukaryota, representando um grupo polifilético de organismos eucariontes que possui características que os diferencia dos organismos pertencentes aos reinos Plantae, Fungi e Animalia. Em geral, os protozoários são organismos unicelulares e heterotróficos, medido micrômetros de comprimento, que habitam ambiente aquáticos marinhos e de água doce ou ainda terrestre quando estabelece associações com animais e plantas.

As doenças parasitárias são consideradas um grave problema de saúde pública e estão associadas principalmente a países subdesenvolvidos, onde o saneamento básico e educação preventiva são precária. As manifestações clínicas que as parasitoses intestinais causam são variadas, pois podem comprometer o bem-estar físico, nutricional e metal.

O gênero Giardia é composto por protozoários flagelados, parasitas intestinais que possuem várias espécies hospedeiras, entre elas o homem. A Giardíase é uma doença gastrointestinal que afeta o pleno potencial das pessoas infectadas, pois exerce uma ação espoliadora de modo indireto que impossibilitar a absorção de gorduras e vitaminas lipossolúveis.

\footnotetext{
${ }^{1}$ Licenciatura em Ciências Biológicas, Instituto Federal do Piauí, fernandasilva952014@gmail.com

${ }^{2}$ Licenciatura em Ciências Biológicas, Instituto Federal do Piauí, igorporleone@gmail.com

${ }^{3}$ Mestre, docente do Instituto Federal do Piauí/ Campus Teresina-Central/DFP, jurecir.silva@ifpi.edu.br

${ }^{4}$ Doutora, docente do Instituto Federal do Piauí/Campus Teresina-Central/DFP, marlucia.lacerda@ifpi.edu.br
} 
A Giardia lamblia é um parasita intestinal que habita o intestino delgado de uma série de mamíferos, incluindo o homem, no qual pode causar diarreia aguda e crônica. Em 2004, a giardíase foi incluída na Iniciativa para as Doenças Negligenciadas da Organização Mundial da Saúde. O presente trabalho teve como objetivo compor uma atividade acadêmico-científicocultural para sensibilizar estudantes do ensino médio e superior de instituição federal pública de ensino em Teresina, Piauí, para a importância de conhecer o protozoário parasita Giardia lamblia e suas consequências para saúde humana, compreendendo as medidas educativas de prevenção para a Giardíase, destacando-a como um problema de saúde pública.

\section{Fundamentação Teórica}

Segundo Neves (2005), a Giárdia e a giardíase têm sido extensivamente estudadas e, apesar dos esforços, várias questões fundamentais ainda continuam sem respostas. A própria taxonomia ainda a controversa, e a determinação das espécies de Giárdia tem sido feita considerando-se o hospedeiro de origem e características morfológicas.

A giardíase está distribuída por todo o planeta, sobretudo em regiões tropicais e subtropicais. No Brasil sua prevalência varia de 12,4\% a 50\%, dependendo do estudo, da região e da faixa etária pesquisada, predominando nas crianças entre zero e seis anos (SANTANA et al., 2014). Molinaro et al., (2012), afirma que no Brasil, a prevalência geral de giardíase oscila, contudo segundo alguns os pesquisadores, de 4 a 30\%. A maior incidência ocorre entre 8 meses e 12 anos de idade, caindo significativamente na fase adulta.

Surtos de giardíase humana estão normalmente associados à contaminação de reservatórios de água para o abastecimento da população. Há maior prevalência da protozoose em regiões tropicais e subtropicais onde as condições sanitárias são precárias e há maior resistência do cisto - que pode se manter viável por vários meses - às condições ambientais (MOLINARO et al., 2012).

A giardíase considerada pela OMS como uma zoonose, sendo a infecção condicionada pela ingestão de cistos. Estes podem permanecer viáveis em ambientes úmidos, por um período de três meses, e resistem à cloração habitual da água (ANDRADE et al., 2010). As condições de vida, moradia e saneamento básico são determinantes para a transmissão do protozoário $G$. lamblia, sendo que a infecção pode ocorrer também através do consumo de água e alimento contaminados com a forma infecciosa do parasita.

Vários fatores estão associados com a disseminação da giardíase, entre eles: água 
contaminada, verduras, legumes e frutas cruas contaminadas pelos cistos; alimentos contaminados por manipuladores parasitados; contato direto de pessoa-a-pessoa através de mãos contaminadas, principalmente creches, asilos, orfanatos e clínicas psiquiátricas; artrópodes, como as mosca e baratas, através dos seus dejetos ou regurgitamento; riachos e reservatórios contaminados pela presença de animais parasitados; e ainda através do sexo analoral (CIMERMAN e CIMERMAN, 2010).

\section{Metodologia}

O estudo foi desenvolvido no Instituto Federal do Piauí/Campus Teresina Central (IFPI/CTC), como pré-requisito da disciplina Parasitologia Humana, compondo uma atividade acadêmico-científico-cultura, apresentada na I Semana de Química e Biologia, cujo públicoalvo era estudantes dos cursos técnicos integrados ao ensino médio, técnico em análises clínicas e cursos de licenciaturas. Inicialmente, foi realizada uma atividade envolvendo os métodos de diagnóstico e identificação parasitária de Giardia lamblia em infusão de alfaces (Lactuca sativa) adquiridas em feiras e supermercados locais. Em seguida, foram preparadas lâminas com o material da infusão para análise microscópica para a identificação dos parasitos. Foi explicado para o público-alvo sobre a importância da higiene dos alimentos e do saneamento básico para a prevenção de doenças, bem como as consequências que a Giardia lamblia pode trazer para a saúde humana.

\section{Resultados e Discussões}

Das duas amostras de alfaces analisadas, nenhuma das amostras apresentou positividade para endoparasitas que causam algum risco à saúde humana. Contudo, a atividade desenvolvida permitiu sensibilizar os participantes para o tema, possibilitando melhor compreensão e assimilação pelos alunos, possibilitando-lhes observar que giardíase e seu agente etiológico é de grande importância, uma vez que esta doença ainda é um grande problema de saúde pública no Brasil e no mundo. Todos tiveram oportunidade de participar da montagem das lâminas e fazer a análise microscópica das mesmas (Figura 1). 


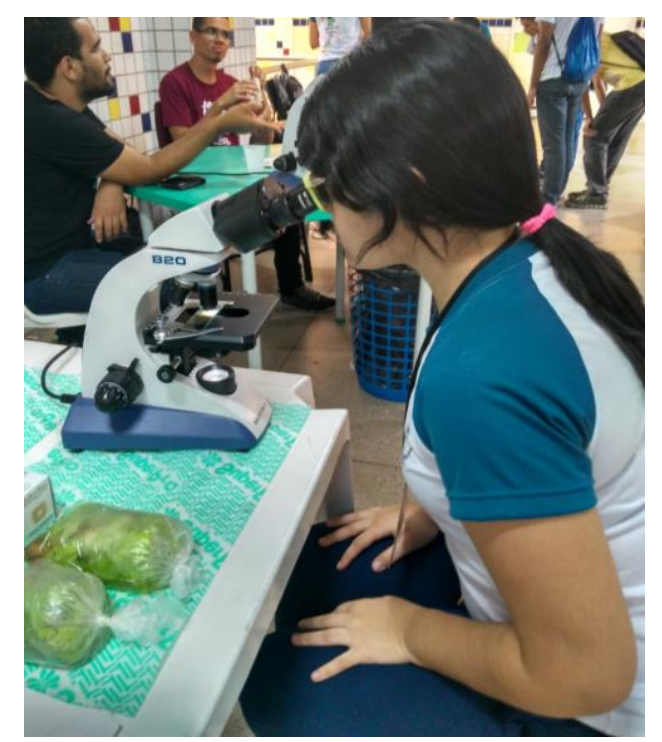

Figura 1: Montagem das lâminas e análise microscópica pelos discentes durante a atividade. Fonte: Própria.

\section{Conclusões}

Esta atividade se fez muito importante, pois possibilitou novos conhecimentos para os participantes e ainda serviu para sensibilizar sobre as complicações para saúde humana provocadas pela giardíase, que mesmo sendo uma parasitose com baixa mortalidade e letalidade, deve ser considerada um problema de saúde pública. Faz-se necessário a implantação de programas de educação em saúde no Instituto Federal do Piauí/Campus Teresina Central e a sensibilização dos discentes para a adoção de bons hábitos de higiene como estratégias importantes para combater esta e outras parasitoses.

\section{Referências}

ANDRADE, E. C. et al. Parasitoses intestinais: uma revisão sobre seus aspectos sociais, Epidemiológicos, clínicos e terapêuticos. Rev. APS, Juiz de Fora, v. 13, n. 2, p. 231-240, 2010. CIMERMAN, B; CIMERMAN, S. Parasitologia humana e seus fundamentos gerais. $2^{\mathrm{a}} \mathrm{ed}$. São Paulo. Atheneu, 2010.

MOLINARO, E. M; CAPUTO, L. F. G; AMENDOEIRA, M. R. R. Conceitos e métodos para formação de profissionais em laboratórios de saúde: volume 5. Rio de Janeiro: EPSJV; IOC,2012.

NEVES, D. P Parasitologia Humana. 11ª edição. São Paulo: Atheneu, p. 121-126, 2005.

SANTANA, L. A. et al. Atualidades sobre giardíase. Jornal Brasileiro de Medicina, v. 102, n. 1, p. $7-10,2014$. 